\title{
Open Surgical Thrombectomy and Coronary Stent Placement for Treatment of Aortic Thrombotic Disease in a Bitch
}

\author{
Wisley lemanjá Malaquias dos Santos', Ariele Aparecida Ferreira', Juliane Lais Roman', \\ Flávio Augusto Vieira Freitag², Vinicius Gonzalez Peres Albernaz', Jorge Luiz Costa Castro ${ }^{3}$, \\ Roberta Carareto' \& Peterson Triches Dornbusch'1
}

\begin{abstract}
Background: The thrombotic aortic disease in dogs and cats is characterized by the pathological formation of blood clots that can rupture and obstruct the blood flow. Abdominal ultrasonography can identify the location and extension of thrombus in the main vasculature and using the doppler it is possible to observe the blood flow around the thrombus. Stents are expandable tube-shaped endoprosthesis characterized as a metal mesh and used to prevent or repair stenoses, allowing liquid, gas, or solids to flow. This report aims to describe the surgical and medical treatment of aortic thrombotic disease followed by coronary stents placement in a bitch.

Case: An 8-year-old Shih Tzu bitch, presented for evaluation of a 1-month progressive hind limbs paresis. Nociception was present in both limbs, but the patient presented discomfort and vocalization when manipulating the pelvic limbs. A complete blood count demonstrated anemia, mild neutrophilia, and lymphopenia. Serum biochemistry found an increase in ALT, ALP, blood urea nitrogen, and CK. Abdominal ultrasonography detected mild bulging of the caudal aorta and trifurcation of the iliac arteries. Increased intraluminal echogenicity and absence of blood flow were also detected using duplex doppler. The initial medical treatment was ineffective in improving clinical signs, therefore surgical repair was performed. The aorta was isolated and clamped with Satinsky forceps and incised. The thrombus fragmented during removal. A non-compliant high-pressure balloon was used to dilated and remove small fragments of blood clots from the right and left external iliac arteries. Coronary stents of $32 \mathrm{~mm}$ length by $2.75 \mathrm{~mm}$ diameter were placed to keep both iliac arteries free. Immediately after the procedure, there was a detectable distal pulse in both hind limbs. Despite intensive medical treatment, the patient evolved to respiratory distress and died on the sixth day after surgery. At necropsy, there were thrombi in the lumen of the arteries and several organs in addition to a large hyaline thrombus occluding $80-90 \%$ of the aortic lumen and left femoral artery. In the trifurcation region, clots were present, and stents placed in the iliac arteries were also occluded.

Discussion: The occurrence of aortic and iliac thrombosis is associated with several conditions, including neoplasia, chronic kidney disease, heart failure, gastric dilatation-volvulus, hypothyroidism, and hyperadrenocorticism (HAC). In this case, the underlying cause of thromboembolism was supposed to be related to an endocrine condition, since the patient had clinical signs compatible with HAC; however, the low-dose dexamethasone suppression test was borderline and further examination could not be afforded. The diagnosis of thrombosis at the iliac trifurcation was obtained through ultrasonographic examination. Computed tomographic and nuclear resonance imaging could have been applied as well. The medical management of the thromboembolic disease was based on anticoagulant therapy with both heparin and clopidogrel in association with surgical thrombectomy and coronary stents placement. Despite the efforts, the patient died shortly after the surgical procedure, which was expected since high rates of mortality and morbidity is often related to the thromboembolic ischemia. The necroscopic examination of the animal found thrombi at the stents, cranial aorta, and microscopically in several tissues. The failure to directly treat the cause of the thrombus, which could not be diagnosed in time, may negatively interfered in patient survival time. The thrombectomy and coronary stents placement reestablished the femoral pulse immediately after surgery, which has been reported in other studies. The surgical resolution of aortic thrombus should be addressed in further studies.
\end{abstract}

Keywords: vascular surgery, aorta artery, ischemic neuropathy.

DOI: $10.22456 / 1679-9216.100478$

Received: 25 February 2020

Accepted: 6 September 2020

Published: 30 September 2020

${ }^{1}$ Department of Veterinary Medicine, Federal University of Paraná (UFPR), Curitiba, PR, Brazil. ${ }^{2}$ Department of Clinical Studies, Ontario Veterinary College, University of Guelph, Guelph, Ontario, Canada. ${ }^{3}$ Department of Veterinary Medicine, Pontifical Catholic University of Paraná (PUCPR), Curitiba. CORRESPONDENCE: V.G.P. Albernaz [vinicius.gp.albernaz@ gmail.com]. Department of Veterinary Medicine. Federal University of Paraná - UFPR. Rua dos Funcionários n. 1540. CEP 80035-050 Curitiba, PR, Brazil. 


\section{INTRODUCTION}

Thrombotic aortic disease in dogs and cats is characterized by a pathological blood clot formation that can rupture and obstruct an arterial blood flow [26]. The formation of a thrombus begins with the platelet activation by exposed tissue collagen and by thrombin action. These two pathways act dynamically in thrombus development, and factors such as shear, blood flow, turbulence, and the number of platelets in circulation can also influence the clot formation [7].

Neurological deficits ranging from pelvic limb weakness to paraplegia can be observed in patients with aortic thrombi [8]. Abdominal ultrasound can identify the location and extension of thrombus in the main vasculature and using duplex doppler it is possible to evaluate the blood flow around it [26].

In medicine, surgery is the treatment of choice for diffuse occlusions involving the aorta and iliac arteries [19]. Therapies such as balloon dilation and endovascular stent angioplasty demonstrate great effectiveness, but due to complications such as pulmonary embolism and vessel occlusion, further studies are needed to safely apply these techniques in veterinary medicine [18]. Stents are an expandable endoprosthesis graft, characterized as a tube-shaped metal mesh used to prevent or repair stenoses, allowing liquid, gas, or solids to flow free [20].

This report aims to describe the surgical procedure, postoperative management, and the use of coronary stents on the treatment of aortic thrombotic disease in a Shih Tzu bitch.

\section{CASE}

An intact, 8-year-old, Shih Tzu bitch, weighing 5,5 kg presented at the Veterinary Hospital of the Federal University of Paraná (HV-UFPR), with polyuria, polydipsia, and a 1-month history of progressive hind limbs paraparesis. The patient presented a proprioceptive deficit in both hind limbs. The right pelvic limb (RPL) had withdrawal reflex and absent patellar reflex while in the left pelvic limb (LPL) a decreased withdrawal reflex and normal patellar reflex were seen. Superficial nociception was present in both hindlimbs and the patient manifested discomfort and vocalization on the manipulation of these limbs. The femoral and metatarsal artery pulse was not audible on doppler evaluation of the LPL, while in RPL it was possible to detect a noisy pulse. The other vital physical parameters were within the normal range.

The complete blood count (CBC) showed anemia (33\% Hematocrit and $10.2 \mathrm{~g} / \mathrm{dL}$ hemoglobin), mild neutrophilia, and lymphopenia. Those in biochemical tests Alanine aminotransferase (ALT) $214.90 \mathrm{~g} / \mathrm{dL}$, alkaline phosphatase (ALP) $335.80 \mathrm{~g} / \mathrm{dL}$, urea $97.9 \mathrm{mg} / \mathrm{dL}$ and creatine kinase (CK) $744.70 \mathrm{~g} / \mathrm{dL}$. Urinalysis showed straw-colored urine, a urinary specific gravity of 1.014, proteinuria $(+1)$, and blood $(+1)$. There was no bacterial growth in the urine culture and antibiogram. A low-dose dexamethasone suppression test via chemiluminescence method had a basal result of 1.2 and $<1.0 \mu \mathrm{g} / \mathrm{dL}$ after 4 hours.

Electrocardiogram and echocardiography examination were unremarkable. Abdominal ultrasonography was performed, showing the following alterations: liver appearance compatible with reactivity or systemic inflammatory/infectious process; gallbladder with moderate cholestasis; and a mild bulging at the caudal aorta, cranial to the iliac arteries trifurcation. In this location, there was a slight enhancement of intraluminal echogenicity and the color duplex Doppler evaluation identified the absence of blood flow. Collateral vessels were present.

The following drugs were administered: carprofen $\left(\text { Rimadyl }^{\circledR}\right)^{1}$ [2.2 mg/kg, BID, SC], methadone $\left(\text { Mytedom }^{\circledR}\right)^{2}[0.3 \mathrm{mg} / \mathrm{kg}$, TID, IM], dipyrone (Analgex $\left.\mathrm{V}^{\circledR}\right)^{3}$ [25 mg/kg TID, IV], gabapentin ${ }^{4}$ [10 mg/kg BID, PO] and heparin $\left(\text { Hemofol }^{\circledR}\right)^{2}[200$ IU/kg QID, IV]. There was no improvement in the initial clinical condition after four days of hospitalization, and therefore a surgical thrombectomy was elected.

Acepromazine $\left(\text { Acepran }^{\circledR}\right)^{5}$ [0.01 mg/kg IV] and methadone $\left(\text { Mytedom }{ }^{\circledR}\right)^{2}[0.2 \mathrm{mg} / \mathrm{kg} \mathrm{IV}]$ were used as pre-anesthetic medication. For anesthetic induction, continuous rate infusion of propofol $\left(\text { Propovan }^{\circledR}\right)^{2}$ at a dose of $1 \mathrm{mg} / \mathrm{kg} / \mathrm{min}$ IV until endotracheal intubation was performed. The patient was maintained with constant rate infusion of propofol at various rates in association with remifentanil $\left(\operatorname{Remifas}^{\circledR}\right)^{2}[10 \mathrm{mcg} / \mathrm{kg} / \mathrm{h}]$ and ketamine $\left(\text { Ketamina }^{\circledR}\right)^{3}[0.6 \mathrm{mg} / \mathrm{kg} / \mathrm{h}]$, diluted in $0.9 \%$ isotonic sodium chloride solution (Physiological Linhamax $\left.{ }^{\circledR}\right)^{6}$. No anesthetic complications were observed during the procedure.

The patient was positioned in dorsal recumbency and a retro-umbilical incision was performed to the pubis. A Gosset retractor and surgical sponges were 


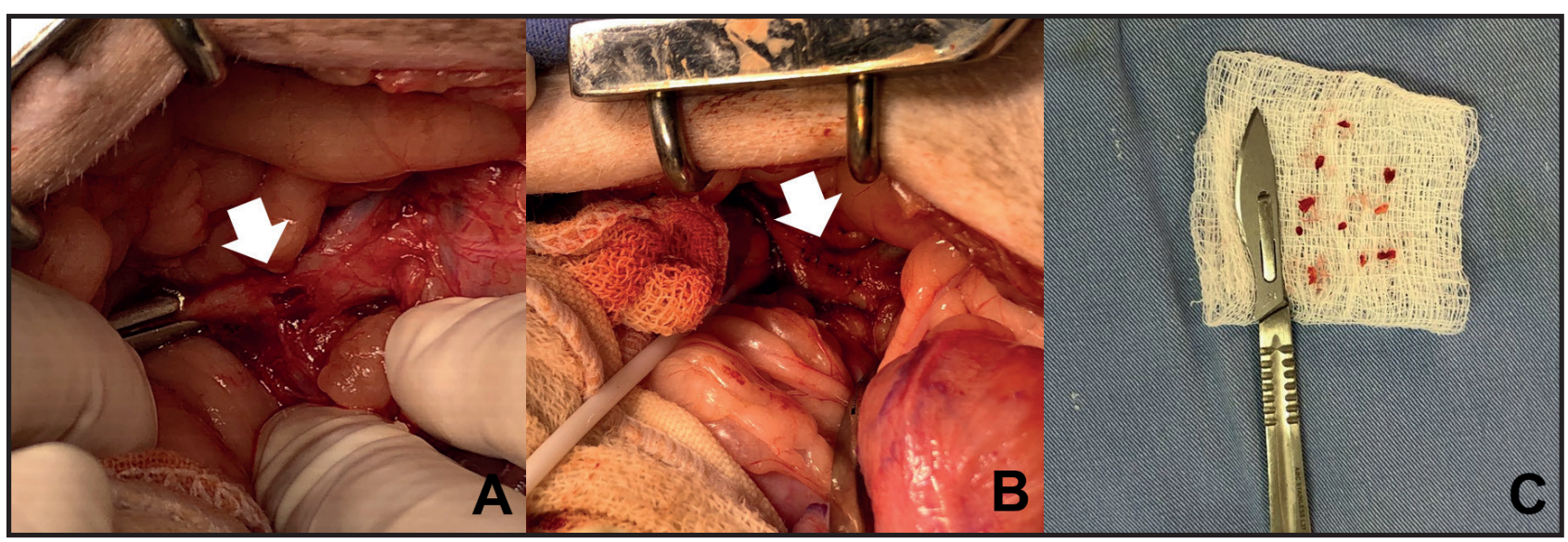

Figure 1. Surgical thrombectomy. A- Aorta artery clamped with Satinsky forceps. The incision made to remove the thrombus is noted. B- Synthesis of the aorta with simple isolated standard sutures with 6-0 polypropylene. C- The removed small aortic thrombi fragments.

used to better exposure and isolation of the abdominal cavity. The final portion of the aorta was isolated and clamped with Satinsky forceps just below the ovarian artery and incised with the aid of a scalpel. The thrombus could be visualized and removed using anatomical forceps. When removing, the thrombus fragmented into several small parts (Figure 1). A non-compliant and high-pressure balloon (Pantera Leo ${ }^{\circledR} 2.25 \mathrm{~mm}$ ) ${ }^{7}$ was introduced caudally into the thrombus and inflated to dilate and remove small fragments when withdrawn from the right and left external iliac arteries. Then a pre-assembled coronary stent (Yukon ${ }^{\circledR}$ Choice 4$)^{8}$ of $32 \mathrm{~mm}$ length by $2.75 \mathrm{~mm}$ diameter was inserted to keep the vessel lumen free. For aortic closure, 6-0 polypropylene ${ }^{9}$ was used in a simple isolated pattern. When removing the Satinsky forceps no blood leakage was observed, and blood perfusion was confirmed due to the presence of a distal pulse. The abdominal wall was closed routinely.

Postoperatively, the patient was referred to the ICU. Heparin $\left(\mathrm{Hemofol}^{\circledR}\right)^{2}$ [200 IU/kg, QID, IV], clopidogrel $\left(\text { Clopiplax }{ }^{\circledR}\right)^{10}[3 \mathrm{mg} / \mathrm{kg}, \mathrm{SID}, \mathrm{PO}]$, and amoxicillin with clavulanate $\left(\text { Clavacilin }^{\circledR}\right)^{11}[22 \mathrm{mg} / \mathrm{kg}$, $\mathrm{SC}$ ] were administered. For analgesia, maropitant citrate $\left(\text { Cerenia }{ }^{\circledR}\right)^{1}[1 \mathrm{mg} / \mathrm{kg}$ BID, IV] associated with lidocaine hydrochloride ${ }^{12}[0.5 \mathrm{mg} / \mathrm{kg} / \mathrm{h}]$ and ketamine $\left(\text { Ketamina }^{\circledR}\right)^{3}[0.6 \mathrm{mg} / \mathrm{kg} / \mathrm{h}]$ constant rate infusion was maintained. In the first two days after surgery, it was possible to measure a strong pulse in both femoral and metatarsal arteries. A slight amount of peritoneal effusion and reactivity of the mesentery tissue were observed in postoperative ultrasonography evaluation. Abdominal radiography demonstrated an adequate stent placement in the iliac arteries (Figure 2). On the third post-operative day, the metatarsal artery pulse was absent and only the femoral arteries had a detectable pulse. A peak of hyperthermia $\left(40^{\circ} \mathrm{C}\right)$ was observed. On the fourth day after surgery, leukocytosis was noted and ceftriaxone $\left(\text { Triaxon }^{\circledR}\right)^{13}[30 \mathrm{mg} / \mathrm{kg}$ BID, IV] was administered. The patient had two episodes of decreased consciousness associated with cyanosis and the pulse in the femoral arteries was not detectable. Blood tests were requested daily to monitor the patient (Table 1).

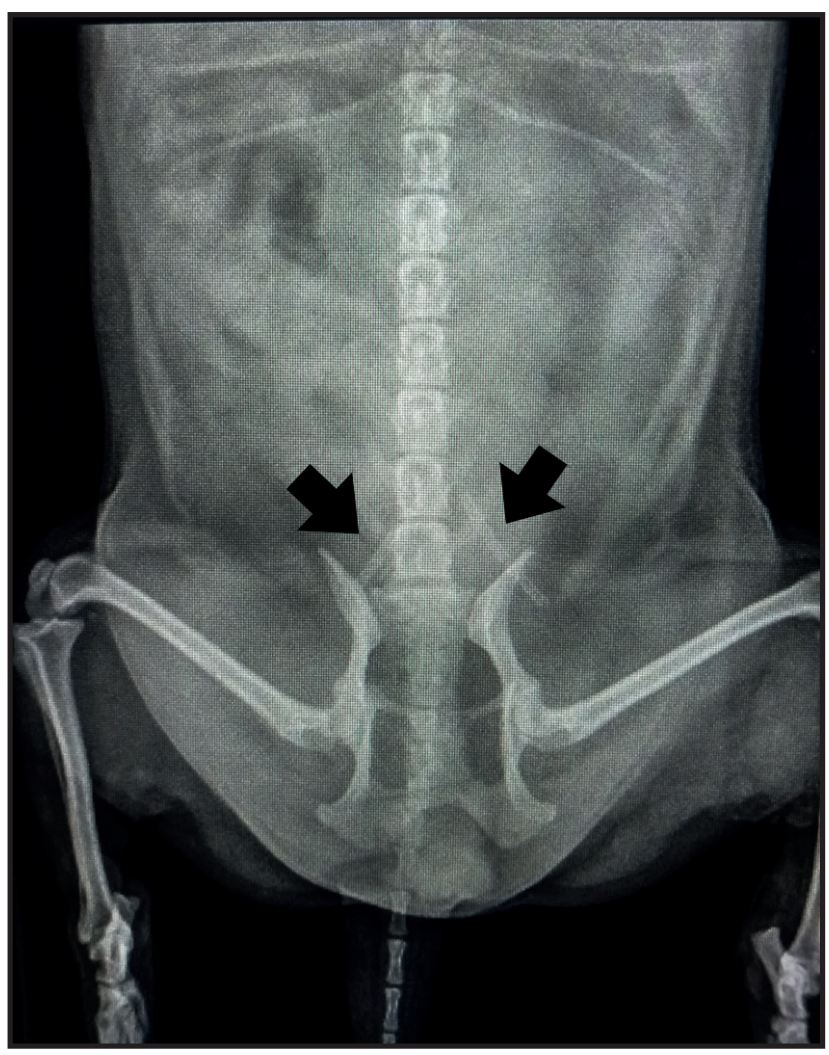

Figure 2. Radiographic image showing the position of metallic stents in iliac arteries. 
W.I.M. Santos, A.A. Ferreira, J.L. Roman, et al. 2020. Open Surgical Thrombectomy and Coronary Stent Placement for Treatment of Aortic Thrombotic Disease in a Bitch.

Acta Scientiae Veterinariae. 48(Suppl 1): 535.

Table 1. Blood tests on days one, two, three, four, and five postoperatively.

\begin{tabular}{lccccc}
\hline Parameter & Day 1 & Day 2 & Day 3 & Day 4 & Day 5 \\
\hline Leukocytes (cells $/ \mathrm{mm}^{3}$ ) & 13,500 & 15,000 & 15,000 & 21,900 & 19,300 \\
Neutrophils (cells $/ \mathrm{mm}^{3}$ ) & 12,550 & 12,750 & 11,550 & 17,082 & 15,826 \\
Band Neutrophils (cells/mm $\left./ \mathrm{mm}^{3}\right)$ & 405 & 405 & 1,350 & 2,847 & 1,158 \\
CK (UI/L) & $5,683.60$ & $1,937.10$ & $1,222.80$ & $4,278.50$ & $2,397.50$ \\
Lactate (mg/dL) & 1.9 & 0.5 & 1.1 & 2.3 & 0.9 \\
Prothrombin time (s) & & & 8.2 & & 8.6 \\
Activate Partial thromboplastin time (s) & & & 13.6 & & 17.6 \\
\hline
\end{tabular}

From the 5th postoperative day beyond, the animal had moments of vocalization, agitation, and tachypnea, requiring oxygen supplementation and sedation with midazolam $\left(\text { Dormium }^{\circledR}\right)^{3}[0.3 \mathrm{mg} / \mathrm{kg} \mathrm{IV}]$. The animal died on the 6th day after surgery.

Necropsy found thrombi in the lumen of several arteries and organs (i.e. lung, kidneys, and spleen) were ischemic. Also, a large hyaline thrombus was attached to the endothelium of the left aortic and femoral artery, occluding $80-90 \%$ of its lumen. In the trifurcation region, clots were present and the stent in the iliac arteries was occluded (Figure 3). No relevant alteration was found in the heart at the macroscopic and microscope examination. The adrenal had moderate, multifocal nodular hyperplasia.

\section{DISCUSSION}

Aortic and iliac thrombosis are associated with neoplasms, chronic kidney disease, cardiac dysfunction, gastric dilatation-volvulus, hypothyroidism, and hyperadrenocorticism (HAC) in dogs [13]. In the present case, it was hypothesized that the underlying cause of thromboembolism would be HAC since the patient exhibit clinical signs compatible with the condition, however, the endocrine test result was in the upper limit. A new exam was requested but could not

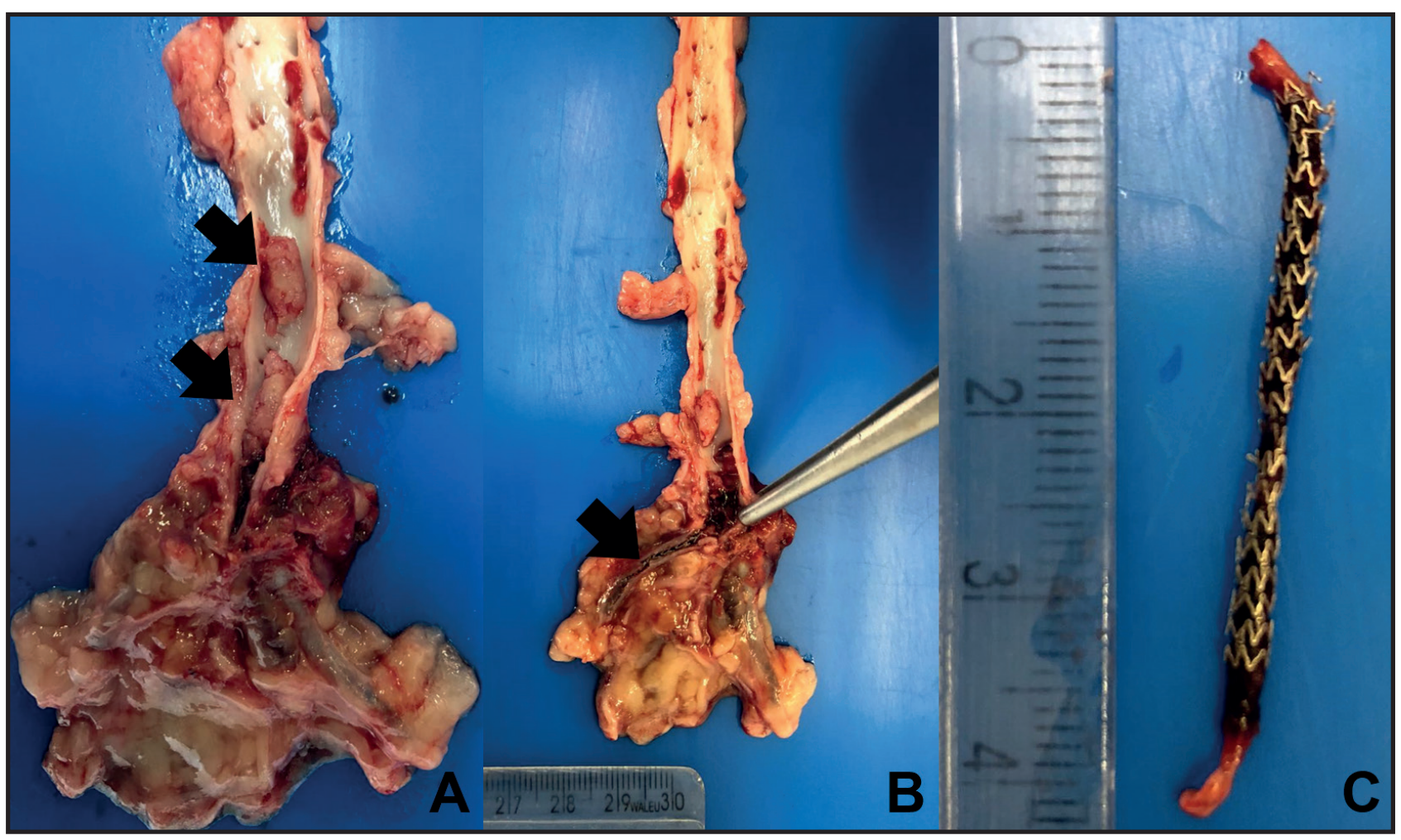

Figure 3. A- Aorta. Note the presence of two hyaline thrombi fragments. B- Aorta, showing the right iliac artery stent. C- Stent removed from the iliac artery obstructed by a large thrombus. 
be afforded. The increased risk of thrombosis in dogs with HAC occurs due to the hypercoagulation status in response to long-term hypercortisolemia [23], so the prognosis of this patient has become reserved in the absence of treatment and late-stage detection of the disease.

The patient presented exercise intolerance, hind limb paresis, absent femoral arterial pulses, and signs of pain as reported previously $[3,8,25]$. However, the chronic form is described as less likely to result in death or euthanasia $[3,14]$. In this case, the patient had a short-term postoperative survival, even facing a chronic thrombotic disease. On the other hand, cases of thromboembolic ischemia have high mortality and morbidity in medicine, with the affected population demonstrating a high risk of short-term death [12].

The location with the highest incidence of aortic thrombi is its distal portion and the external iliac arteries. In a study, $40 \%$ of the patients had thrombi in this segment and $28 \%$ in the internal and external iliac arteries [14]. In this case, necropsy revealed that the patient had thrombi affecting the distal portion of the aorta to the femoral arteries.

Schwede et al. [21] conducted a study where tomography confirmed the previous diagnosis of ultrasound. The diagnosis of thrombi can be made by ultrasonography examination of the abdomen, computed tomography, and nuclear magnetic resonance [17]. Also, vascular ultrasound combined with abdominal radiography can be used as a possible replacement for angiotomography [17]. In this report, the thrombus in the iliac trifurcation region was diagnosed by ultrasound examination. The ultrasound detection can suggest it was an old thrombus because the appearance did not agree with the anechogenic aspect, as the blood itself, reported in recent thrombi [22].

Regarding antithrombotic therapy, a protocol with the use of non-steroidal anti-inflammatory drugs was instituted, which besides the analgesic function, does not inhibit prostacyclin which is a potent inhibitor of platelet aggregation [11]. Platelet aggregation was controlled including clopidogrel at the dose of $3 \mathrm{mg} / \mathrm{kg}$ described in felines for platelet inhibition [10] and in medicine for prophylaxis of thromboembolic events $[9,15]$.

As anticoagulant therapy, heparin was reported to influence the formed thrombi and preventing further growth of new thrombi [13]. There is no defined protocol for heparin dose in dogs, however, a study suggests the effect of $200 \mathrm{IU} / \mathrm{kg}$ in healthy dogs, which resulted in sustained plasma heparin concentrations for the treatment or prevention of thrombosis without an increased bleeding risk [6]. However. the initial dose of $200 \mathrm{IU} / \mathrm{kg}$ did not increase the activated partial thromboplastin time (APTT) significantly and was subsequently increased to $400 \mathrm{IU} / \mathrm{kg}$. When using heparin, daily APTT should be evaluated. However, in this case, APTT reevaluation was not a daily basis. Frequent evaluation could have led to adjustments in heparin dose and inhibition of new thrombus formation.

The use of intravenous heparin bolus (80 IU/kg) at diagnosis followed by constant rate infusion (18 IU/kg/h) associated with $0.5 \mathrm{mg} / \mathrm{kg}$ acetylsalicylic acid was suggested [18]. Similarly, other authors used heparin at the beginning of the surgery [21]. Both authors had successful outcomes, thus suggesting that this therapeutic approach are viable options in cases of aortic thrombosis.

Warfarin, a vitamin $\mathrm{K}$ antagonist, was cited to be superior to heparin as an anticoagulant in two reported cases of aortic thrombus resolution with no bleeding events or complications [27]. Other protocols to prevent the formation of new thrombi is the association of heparin and warfarin. An associated antithrombotic therapy could have brought benefit to the patient hereby described.

Thrombectomy is a rarely reported procedure in veterinary medicine. Two cases of thrombectomy were described but focused on postoperative therapy and do not describe the surgical technique [27]. One of them was treated with aspirin and had a 16-month survival until euthanasia due to the recurrence of the aortic thrombus. The other dog showed no improvement and was euthanized early after surgery.

A Fogarty catheter was used in a case for arterial embolectomy through a small arteriotomy [21]. In this case, the thrombus has not adhered to the arterial walls, which made it possible to remove using the catheter balloon and a small incision [21]. In our case report, it was difficult to remove the thrombi with a balloon, due to the chronic adhesions and so a large arteriotomy was performed. The thrombi were removed in parts, eventually allowing some detached material to obstruct the artery when the flow was reestablished.

Another case was successfully treated with the thrombus removed through an arteriotomy [18]. In that patient, CK was initially slightly increased, doubling 
its value overnight as the disease progressed, which was indicative of damage or necrosis of myocytes and hepatocytes. In our case, CK was elevated, decreased in the immediate postoperative period, and increased again as new thrombi formed and ischemia progressed, which was observed later at necropsy.

The surgical and medical complication rate of open surgery and endovascular repairs are reported to be similar, however, minimally invasive techniques had a lower length of hospitalization and intensive care units stay [1]. To our knowledge, only open surgery has been reported in veterinary medicine.

In human patients, when there is an aortic thrombosis cranial to the kidney, distally located obstruction associated with proximal (towards the renal arteries) thrombi or calcifications of the aortic wall, open surgical approach is indicated to ensure definitive repair [1]. In our patient, the thrombi were located caudal to the renal arteries, and so there was a possibility of a minimally invasive therapy, however, the adherent characteristic of these thrombi precludes the minimally invasive procedures. Therefore, we used the balloon to remove the recent thrombi in association with a clamp for attached thrombi, and a stent to keep the vessel lumen viable.

In a case report, on the first postoperative day, the patient had pelvic limb edema and acidosis, indicating a ischemia-reperfusion syndrome [21]. In our case, the animal did not have clinical signs compatible with reperfusion syndrome in the immediate postoperative period. Despite being used for analgesia, lidocaine has been also indicated to avoid reperfusion syndrome [19].

In medicine, intra-stent stenosis has a prevalence of $20-30 \%$ [24]. The occurrence of stent thrombosis is often associated with catastrophic consequences, such as acute vessel occlusion, which can lead to sudden death. It is not possible to state whether thrombosis occurred due to stent occlusion as it also occurred in other vessels.
Limitations of this case include lack of some exams, poor consensus on protocols for treat thrombosis, and surgical approaches in dogs. Difficult access to tests such as thromboelastography $\left(\mathrm{TEG}^{\circledR}\right)$ negatively impact decision-making and management of this patient. TEG is a laboratory method that demonstrates viscoelastic changes in blood, as well as standard coagulation profiles, and has been used as an additional mean to access coagulation and hypercoagulability states [14]. In medicine, it has been used to evaluate the postoperative coagulation status of several patients [2].

Acute aortic thrombosis should be considered as a differential diagnosis in dogs with paraplegia and can be easily detected in the absence of a femoral pulse. In this case, surgical thrombectomy and coronary stent placement reestablished the arterial blood flow in the affected region. Although the patient had short-term complications that lead to early death, the technique has been described in other studies and future researches should be conducted to elucidate the actual role of these procedures in treating dogs with thrombotic conditions.

\section{MANUFACTURERS}

\author{
${ }^{1}$ Zoetis Brasil. São Paulo, SP, Brazil. \\ ${ }^{2}$ Cristália Produtos Químicos Farmacêuticos Ltda. Itapira, SP, \\ Brazil. \\ ${ }^{3}$ União Química Farmacêutica Nacional S/A. São Paulo, SP, Brazil. \\ ${ }^{4}$ DrogaVet Farmácia de Manipulação Veterinária. Curitiba, PR, \\ Brazil. \\ ${ }^{5}$ Vetnil indústria e Comércio de Produtos Veterinários Ltda. Jacareí, \\ SP, Brazil. \\ ${ }^{6}$ Eurofarma Brasil. São Paulo, SP, Brazil. \\ ${ }^{7}$ Biotronik. Baar, Switzerland. \\ ${ }^{8}$ Translumina GmbH. Hechingen, Germany. \\ ${ }^{9}$ Bioline Fios Cirúrgicos Ltda. Anápolis, GO, Brazil. \\ ${ }^{10}$ Germed Pharma. Campinas, SP, Brazil. \\ ${ }^{11}$ Norbrook do Brasil Produtos Veterinários e Farmacêuticos Ltda. \\ São Paulo, SP, Brazil. \\ ${ }^{12}$ Hipolabor Farmacêutica Ltda. Sabará, MG, Brazil. \\ ${ }^{13}$ Blau Farmacêutica. Cotia, SP, Brazil.
}

Declaration of interest. The authors report no conflicts of interest. The authors alone are responsible for the contents and writing of the paper.

\section{REFERENCES}

1 Antonello M., Squizzao F., Bassini S., Porcellato L., Grego F. \& Piazza M. 2019. Open repair versus endovascular treatment of complex aortoiliac lesions in low-risk patients. Journal of Vascular Surgery. 70: 1155-1165. DOI: 10.1016/j. jvs.2018.12.030

2 Bruno B., Maurella C., Falco S., Tarducci A., Zanatta R., Gianella P., D’Angelo A., Piras L., Di Bella A. \& Borrelli A. 2015. Assessment of coagulation utilizing thromboelastometry in dogs undergoing orthopedic surgery. Journal of Veterinary Emergency and Critical Care. 25: 358-363. DOI: 10.1111/vec.12300 
3 Boswoocd A., Lamb R. \& White R.N. 2000. Case reports Aortic and iliac thrombosis in six dogs. Journal of Small Animal Practice. 41: 109-114. DOI: 10.1111/j.1748-5827.2000.tb03176.x

4 Carvalho C. F., Chammas M.C., Sterman F.A., Barros N. \& Cerri G.G. 2008. Ultrassonografia dúplex-Doppler na avaliação morfológica e hemodinâmica das artérias aorta e mesentérica cranial em cães. Brazilian Journal of Veterinary Research and Animal Science. 45(1): 24-31. DOI: 10.11606/issn.1678-4456.bjvras.2008.26716.

5 Diamante G.A.C., Marinho P.V.T., Zani C.C., Bracarense A.P.F.R.L. \& Arias M.V.B. 2016. Tromboembolismo aórtico decorrente de endocardite bacteriana causando neuromiopatia isquêmica em um cão. Acta Scientiae Veterinariae. 44(1): $1-5$.

6 Diquélou A., Barbaste C., Gabaig A.M., Trumel C., Abella-Bourges N., Guelfi J.F. \& Bousquet-Mélou A. 2005. Pharmacokinetics and pharmacodynamics of a therapeutic dose of unfractionated heparin (200 U/kg) administered subcutaneously or intravenously to healthy dogs. Veterinary Clinical Pathology. 34(3): 237-42. DOI: 10.1111/j.1939165x.2005.tb00047.x

7 Furie B. \& Furie B.C. 2008. Mechanisms of Thrombus Formation. The New England Journal of Medicine. 359: 938949. DOI: 10.1056/NEJMra0801082.

8 Gonçalves R., Pederis J., Chang Y.P., Zoia A., Mosley J. \& Anderson T.J. 2008. Clinical and neurological characteristics of aortic thromboembolism in dogs. Journal of Small Animal Practice. 49: 178-184. DOI: 10.1111/j.17485827.2007.00530.x.

9 Gurbel P. A. 2003. Clopidogrel for Coronary Stenting: Response Variability, Drug Resistance, and the Effect of Pretreatment Platelet Reactivity. Circulation. 107(23): 2908-2913. DOI: 10.1161/01.CIR.0000072771.11429.83

10 Hogan D.F., Andrews D.A., Green H.W., Talbott K.K., Ward M.P. \& Calloway B.M. 2004. Antiplatelet effects and pharmacodynamics of clopidogrel in cats. Journal of the American Veterinary Medical Association. 225: 1406-1411. DOI: 10.2460/javma.2004.225.1406

11 Isaacs J.P. 1996. Adverse effects of non-steroidal anti-inflammatory drugs in the dog and cat. Australian Veterinary Practioner. 26(40): 180-186.

12 Kempe K., Starr B., Stafford J.M., Islam A., Mooney A., Lagergren E., Corriere M.A. \& Edward M.S. 2014. Results of surgical management of acute thromboembolic lower extremity ischemia. Journal of Vascular Surgery. 3: 702-707. DOI: 10.1016/j.jvs.2014.03.273

13 Konecny F. 2010. Thromboembolic conditions, aetiology diagnosis, and treatment in dogs and cats. Acta Veterinaria Brunensis. 79: 497-508. DOI: 10.2754/avb201079030497.

14 Lake-Bakaar G., Johnson E.G. \& Griffiths L.G. 2012. Aortic thrombosis in dogs: 31 cases (2000-2010). Journal of the American Veterinary Medical Association. 241(7): 910-915. DOI: 10.2460/javma.241.7.910

15 Lorga-Filho A.M., Azmus A.D., Soeiro A.M., Quadros A.S., Avezum-Junior A., Marques A.C., Franci A., Manica A.L.L., Volschan A., De Paola A.A.V., Greco A.I.L., Ferreira A.C.N., Sousa A.C.S., Pesaro A.E.P., Simão A.F., Lopes A.S.S.A., Timerman A., Ramos A.I.O., Alves B.R., Caramelli B., Mendes B.A., Polanczyk C.A., Montenegro C.E.L., Barbosa C.J.D.G., Serrano Junior C.V., Melo C.C.L., Pinho C., Moreira D.A.R., Calderaro D., Gualandro D.M., Armaganijan D., Machado-Neto E.A., Bocchi E.A., Paiva E.F., Stefanini E., D'Amico E., Evaristo E.F., Silva E.E.R., Fernandes F., Brito-Junior F.S., Bacal F., Ganem F., Gomes F.L.T., Mattos F.R., Moraes-Neto F.R., Tarasoutchi F., Darrieux F.C.C., Feitosa G.S., Fenelon G., Morais G.R., Correa-Filho H., Castro I., GonçalvesJunior I., Atié J., Souza-Neto J.D., Ferreira J.F.M., Nicolau J.C., Faria-Neto J.R., Annichino-Bizzacchi J.M., Zimerman L.I., Piegas L.S., Pires L.J.T., Baracioli L.M., Silva L.B., Mattos L.A.P., Lisboa L.A.F., Magalhães L.P.M., Lopes M.A.C.Q., Montera M.W., Figueiredo M.J.O., Malachias M.V.B., Gaz M.V.B., Andrade M.D., Bacellar M.S.C., Barbosa M.R., Clausell N.O., Dutra O.P., Coelho O.R., Yu P.C., Lavítola P.L., Lemos-Neto P.A., Andrade P.B., Farsky P.S., Franco R.A., Kalil R.A.K., Lopes R.D., Esporcatte R., Heinisch R.H., Kalil-Filho R., Giraldez R.R.C.V., Alves R.C., Leite R.E.G.S., Gagliardi R.J., Ramos R.F., Montenegro S.T., Accorsi T.A.D., Jardim T.S.V., Scudeler T.L., Moisés V.A. \& Portal V.L. 2013. Sociedade Brasileira de Cardiologia - Diretrizes brasileiras sobre antiagregantes plaquetários e anticoagulantes em cardiologia. Arquivos Brasileiros de Cardiologia. 101(3): 1-95.

16 Mayhew P.D., Culp W.T.N., Balsa I.M. \& Zwingenberger A.L. 2017. Phrenicoabdominal venotomy for tumor thrombectomy in dogs with adrenal neoplasia and suspected vena caval invasion. Veterinary Surgery. 47(2): 1-9. DOI: $10.1111 /$ vsu. 12728 
17 Moraes Filho D., Trevisan F.B., Silvestre J.M.S., Sardinha W.E., Ramires E.D., Dias S.V.M. \& Matsuda H. 2014. Vascular ultrasonography for follow-up of endovascular repair of abdominal aorta aneurysms. Jornal Vascular Brasileiro. 13(3): 168-174. DOI/: 10.1590/jvb.2014.019

18 Narak J., Graff E.C., Saile K. \& Tillson D.M. 2015. Surgical Removal of a Canine Aortic Thromboembolism Secondary to Pancreatitis. Case Reports in Veterinary Medicine. 2015: 1-7. DOI: 10.1155/2015/842076

19 Norgren L., Hiatt W.R., Dormandy J.A., Nehler M.R., Harris K.A. \& Fowkes F.G.R. 2007. Inter-society consensus for the management of peripheral arterial disease (TASC II). Journal of Vascular Surgery. 45: S5-S67. DOI: 10.1016/j. jvs.2006.12.037

20 Patil PB., Talekar S.H., Patil D.B., Parikh P.V \& Pateal A.M. 2014. Animal for stents or stents for animal - an area under construction. Journal of Pharmaceutical Biology. 4(4): 167-172.

21 Schwede M., Richte O., Alef M., Theuß T. \& Loderstedt S. 2018. Vascular surgery of aortic thrombosis in a dog using Fogarty maneuver - technical feasibility. Clinical Case Reports. 6(1): 214-219. DOI: 10.1002/ccr3.1295

22 Spaulding K.A. 1997. A review of sonographic identification of abdominal blood vessels and juxtavascular organs. Veterinary Radiology and Ultrasound. 38(1): 4-23. DOI: 10.1111/j.1740-8261.1997.tb01597.x

23 Teshima T., Hara Y., Taoda T., Koyama H., Takahashi K., Nezu Y., Harada Y., Yogo T., Nishida K., Osamura R., Teramoto A. \& Tagawa M. 2008. Cushing's Disease Complicated with Thrombosis in a Dog. Journal of Veterinary Medical Science. 70: 487-491. DOI: 10.1292/jvms.70.487

24 Thippara-Bina R., Khan W. \& Domb A.J. 2013. Eluting combination drugs from stents. International Journal of Pharmaceutics. 454(1): 4-10. DOI: 10.1016/j.ijpharm.2013.07.005

25 Van Winkle T., Hackner S.G. \& Liu S.M. 1993. Clinical and pathological features of aortic thromboembolism in 36 dogs. Journal of Veterinary Emergency and Critical Care. 3: 13-21. DOI: 10.1111/j.1476-4431.1993.tb00099.x

26 Williams T.P.E., Shaw S., Porter A. \& Berkwitt L. 2017. Aortic thrombosis in dogs. Journal of Veterinary Emergency and Critical Care. 27(1): 9-22. DOI: 10.1111/vec.12527

27 Winter R.L., Sedacca C.D., Adams A. \& Orton E.C. 2012. Aortic thrombosis in dogs: Presentation, therapy, and outcome in 26 cases. Journal of Veterinary Cardiology. 14(2): 333-342. DOI: 10.1016/j.jvc.2012.02.008 